\title{
Kinetic differentiation of bulk/interfacial oxygen reduction mechanisms at/near liquid/liquid interfaces using scanning electrochemical microscopy
}

\author{
Haiqiang Deng a , Pekka Peljo ${ }^{\text {a,b }}$, Dmitry Momotenko ${ }^{\text {a,c }}$, Fernando Cortés-Salazar ${ }^{a}$, T. Jane Stockmann ${ }^{a}$, \\ Kyösti Kontturi ${ }^{\mathrm{b}}$, Marcin Opallo ${ }^{\mathrm{d}}$, Hubert H. Girault ${ }^{\mathrm{a}, *}$ \\ a Laboratoire d'Electrochimie Physique et Analytique, Ecole Polytechnique Fédérale de Lausanne (EPFL), Station 6, CH-1015 Lausanne, Switzerland \\ ${ }^{\mathrm{b}}$ Department of Chemistry, Aalto University, P.O. Box 16100, 00076, Finland \\ ${ }^{\mathrm{C}}$ Department of Chemistry, University of Warwick, Gibbet Hill Road, CV4 7AL, United Kingdom \\ d Institute of Physical Chemistry, Polish Academy of Sciences, ul. Kasprzaka 44/52, 01-224 Warszawa, Poland
}

\section{A R T I C L E I N F O}

\section{Article history:}

Received 11 July 2014

Received in revised form 19 August 2014

Accepted 21 August 2014

Available online 16 September 2014

\section{Keywords:}

ITIES

Oxygen reduction

Decamethylferrocene

SECM

Catalytic EC'

\begin{abstract}
A B S T R A C T
The present work describes the application of scanning electrochemical microscopy (SECM) in the feedback mode to determine the kinetics of oxygen reduction at or near the liquid/liquid interface - between water and 1,2-dichloroethane (w/DCE). The system contained decamethylferrocene (DMFc) in DCE as the electron donor and acids in water as a proton source. In this approach, decamethylferrocenium (DMFc ${ }^{+}$) is reduced at the tip of a microelectrode in DCE and the electrogenerated DMFC reacts with protons and oxygen to be re-oxidized in a following chemical reaction (catalytic EC' mechanism). When a high Galvani potential difference was applied across the liquid/liquid interface, protons would transfer rapidly to the organic phase. Under this condition, SECM approach curves toward the liquid/liquid interface showed dramatic current increases at distances far from the interface. This indicates that oxygen reduction takes place mainly in the bulk DCE; however, at lower Galvani potential differences, where the proton transfer is slow, oxygen reduction was also observed at the interface. Finally, SECM feedback mode measurements with the tip approaching a conductive substrate were used to determine the kinetics of the homogeneous reaction, with an obtained apparent rate constant of $0.2-0.5 \mathrm{~m}^{3} \mathrm{~mol}^{-1} \mathrm{~s}^{-1}$.
\end{abstract}

(c) 2014 Elsevier B.V. All rights reserved.

\section{Introduction}

In aerobic organisms, the oxygen reduction reaction (ORR) in cellular respiration is a proton-coupled electron-transfer (PCET) process, where the proton transfer and electron transfer are tightly coupled via enzymes containing porphyrin subunits as active centers bounded within the biomembrane of the mitochondria - a soft interface $[1,2]$. During this process, nutrients are oxidized to generate adenosine triphosphate (ATP), the so-called "energy currency" used in metabolism. Oxygen has been recognized as the terminal electron acceptor with water $\left(\mathrm{H}_{2} \mathrm{O}\right)$ as its main reduction product, although sometimes superoxide intermediates can be also generated under some unfavorable conditions.

In 1963, Blank and Feig pointed out that to a rough approximation, there is a similarity between one half of a biomembrane and a liquid/liquid interface [3]. The liquid/liquid interface or the

\footnotetext{
* Corresponding author. Tel.: +41 21693 3145; fax: +41 216933667.

E-mail address: hubert.girault@epfl.ch (H.H. Girault).
}

interface between two immiscible electrolyte solutions (ITIES) is normally composed of two phases between water (w) and an organic solvent (o), such as 1,2-dichloroethane (DCE) or nitrobenzene (NB) [4,5]. Since then, the liquid/liquid interface was employed as a simplified model to investigate bio-electrical phenomena such as potentials and currents at biomembranes and spread into the field of electrophysiology. The potential across the ITIES, i.e. the Galvani potential difference $\left(\Delta_{o}^{\mathrm{w}} \phi\right)$, functioning as the driving force for ion transfer, can be controlled either by a common ion distribution between the two phases or externally by way of a potentiostat and electrodes immersed in each phase $[4,5]$. The method employed in practical applications depends on the specific aims, although the latter is more commonly used. Until now, the four-electrode systems [6], three-electrode systems [7,8], and supported micro- or nano-ITIES [9], constitute the main body of the methodology in externally polarizing the ITIES.

The ORR at the ITIES has been investigated extensively for $\mathrm{ca}$. two decades [10]. The pioneering work of Schiffrin's group in 1995 employed ferrocene (Fc) and its derivatives, 1,1'-dimethylferrocene 
(DFc) or decamethylferrocene (DMFc) as electron donors located in the organic phase [10]. They observed an enhanced current without a reverse peak in the positive Galvani potential range when oxygen was used as the only oxidant in the aqueous phase; they ascribed this phenomenon to sequential oxygen reduction with water as the final product [10]. However, no efforts were made to elucidate the reaction mechanism. In 2000, Kihara and co-workers [11] studied ORR at the w/DCE interface by polarography in the presence of tetrachlorohydroquinone in DCE as the lipophilic electron donor at different aqueous $\mathrm{pH}$ values. It was shown that $\mathrm{H}_{2} \mathrm{O}$ or hydrogen peroxide $\left(\mathrm{H}_{2} \mathrm{O}_{2}\right)$ was the final product depending on the applied Galvani potential difference [11]. Similarly, Anson's group employed a thin organic layer containing a catalyst, cobalt 5,10,15,20-tetraphenylporphyrin or cobalt "picket fence" porphyrin, supported on a graphite electrode, to study the electro-reduction of oxygen at the liquidliquid interface $[12,13]$. It was found that the rate of the ORR and the fraction of $\mathrm{H}_{2} \mathrm{O}$ produced could be improved significantly by introduction of the thin organic layer interposed between the solid electrode and the aqueous phase, in comparison with the catalyst adsorbed directly on the solid electrode [12,13]. In 2003, reduction of molecular oxygen in the aqueous phase by a fullerene monoanion located in the oil phase was reported by Kontturi and co-workers and characterized by scanning electrochemical microscopy (SECM) [14]. Samec and co-workers have demonstrated that platinum nanoparticles can be synthesized in situ and adsorbed at the ITIES acting as catalysts for the interfacial reduction of oxygen [15]. Our group has also investigated the ORR at the w/DCE interface quite extensively since 2008 [16], including the ORR at the ITIES by direct lipophilic electron donors such as different ferrocene derivatives [1618] or tetrathiafulvalene [19]. We also found that the reaction can be catalyzed by different porphyrins [20-27] and dodecylaniline [28], and a novel fuel cell concept based on molecular catalysis of oxygen reduction at a liquid/liquid interface was introduced [29]. More recently, the mechanism of ORR catalyzed by the biomimetic cofacial bis-metalloporphyrins at the liquid/liquid interface was also studied, with the help of density functional theory (DFT) [30]. Interestingly, a recent work from Opallo's group showed that $\mathrm{H}_{2} \mathrm{O}_{2}$ can be generated from ORR in biphasic systems under conditions unfavorable for proton transfer, while being detected in situ by SECM with the help of an enzyme - horseradish peroxidase [31]. They also demonstrated the successful determination of $\mathrm{H}_{2}$ produced in a biphasic liquid/liquid system employing a potentiometric probe [32].

Although the biphasic ORR has been studied intensively, the kinetic aspects of this reaction have been missed for some time and only addressed in few studies [33,34]. Recently, the kinetics of biphasic ORR by Fc and its derivatives as the lipophilic electron donors, along with sulfuric acid as the aqueous proton source, were investigated through comparison of experimentally observed voltammograms to simulated ones generated by COMSOL Multiphysics utilizing the finite element method (FEM) [35]. The reaction pathway was shown to be composed of a potential dependent proton transfer step (i.e. ion transfer, IT) from the aqueous to organic phases along with two homogeneous chemical reactions $\left(C_{1} C_{2}\right)$ occurring in the organic phase - an IT $-C_{1} C_{2}$ mechanism [35]. In that study, the reaction between DMFc and $\mathrm{H}^{+}(\mathrm{o})$ to form DMFchydride $\left(\mathrm{DMFc}-\mathrm{H}^{+}\right)$was considered the first step $\left(\mathrm{C}_{1}\right)$, while reaction of DMFc- $\mathrm{H}^{+}$with oxygen to form a hydrogen peroxyl radical species $\left(\mathrm{HO}_{2}^{-}\right)$and DMFc ${ }^{+}$was recognized as the second step $\left(\mathrm{C}_{2}\right)$. The following reactions, between $\mathrm{HO}_{2}^{-}$and another DMFc and $\mathrm{H}^{+}$ forming $\mathrm{H}_{2} \mathrm{O}_{2}$ and $\mathrm{DMFc}^{+}$, were considered to be fast and irreversible.

Herein, an alternative methodology employing SECM in the feedback mode was developed to study the mechanism and kinetics of the ORR at the ITIES. It should be mentioned that an earlier work surrounding in situ SECM detection of $\mathrm{H}_{2} \mathrm{O}_{2}$ produced in a
w/DCE biphasic reaction has been reported [17]; however, no kinetic/thermodynamic information was obtained, while the work presented here will address this missing component and provide new physical, mechanistic insights. SECM in the feedback mode implements a microelectrode probe approaching or scanning over an interface, while recording the current generated by a redox mediator. Depending on the capability of the interface to regenerate the initial redox species, a current change monitored at the microelectrode allows the extraction of kinetic information by taking into account the balance between rates of electron transfer and mass transport processes. Therefore, SECM is an excellent tool to study interfacial phenomena [36,37], such as electron transfer at liquid/liquid interfaces [38,39], as well as homogeneous chemical reactions involving redox species generated at the SECM probe [40-44]. For instance, Bard and co-workers have employed SECM for rapid screening of metallic catalysts deposited on a solid substrate in acidic media for oxygen reduction $[45,46]$.

Specifically, a decamethylferrocenium $\left(\mathrm{DMFc}^{+}\right)$solution was prepared firstly by a biphasic reaction [16]. Then $\mathrm{DMFc}^{+}$was reduced to DMFc at the tip of a microelectrode in DCE and the electrogenerated DMFc reacts with protons (either from aqueous in a liquid/liquid interface system or from an organic acid) and dissolved oxygen to be re-oxidized in a EC' scheme [47]. Steady-state microelectrode voltammetry has been previously employed to measure the kinetics of a catalytic EC' process [48], but SECM feedback measurements offer some further advantages featured with the tunable kinetic and mass transfer regimes [49]; therefore, this methodology has been adopted for this work.

\section{Theory}

\subsection{Mechanism of oxygen reduction by DMFc}

The overall oxygen reduction by DMFc at the liquid/liquid interface is described by reaction 1 [16], in which $\mathrm{H}^{+}$is initially in the aqueous phase.

$2 \operatorname{DMFc}(\mathrm{o})+\mathrm{O}_{2}(\mathrm{o})+2 \mathrm{H}^{+}(\mathrm{o}) \stackrel{k}{\rightarrow} 2 \mathrm{DMFc}^{+}(\mathrm{o})+\mathrm{H}_{2} \mathrm{O}_{2}(\mathrm{w})$

where $\mathrm{o}=\mathrm{DCE}$, and $\mathrm{w}=$ aqueous. Reaction 1 is composed of the individual steps shown in reactions $2-4$, occurring in the oil phase. For reaction 1 to occur, $\mathrm{H}^{+}$needs to be transferred into the oil phase from water, either by an external electrical polarization or by phase transfer catalysis with an addition of extremely lipophilic counteranion.

$$
\mathrm{DMFc}+\mathrm{H}^{+} \stackrel{k_{1}}{\rightarrow} \mathrm{DMFCH}^{+}
$$

$\mathrm{DMFCH}^{+}+\mathrm{O}_{2} \stackrel{k_{2}}{\rightarrow} \mathrm{DMFc}^{+}+\mathrm{HO}_{2}$

$\mathrm{HO}_{2}^{\cdot}+\mathrm{DMFC}+\mathrm{H}^{+} \stackrel{k_{3}}{\rightarrow} \mathrm{H}_{2} \mathrm{O}_{2}+\mathrm{DMFc}^{+}$

The rate determining step has been found to be the protonation of DMFc to form the hydride - DMFc- ${ }^{+}$(Eq. (2)) $[35,50]$. The hydride can then react with oxygen to produce $\mathrm{DMFc}^{+}$and the hydrogen peroxyl radical (Eq. (3)) that then reacts quickly with a proton and an equivalent of DMFc to produce $\mathrm{H}_{2} \mathrm{O}_{2}$ (reaction 4) $[35,50]$. It has been shown by FEM simulations that reaction 3 can still influence the kinetics of the overall reaction (Eq. (1)) appreciably, even though the reaction described in Eq. (2) is the rate determining step [35]. The $\mathrm{H}_{2} \mathrm{O}_{2}$ produced then partitions into the aqueous phase. Hence the total rate of DMFc consumption can be estimated by taking the steady-state assumption for the inter- 
mediate species $-\mathrm{DMFCH}^{+}$and $\mathrm{HO}_{2}$ and assuming fast diffusing $\mathrm{O}_{2}$ can be replenished during the course of the reaction. The rate of the overall reaction can then be expressed approximately as

$\frac{\mathrm{d}\left[\mathrm{DMFc}^{+}\right]}{\mathrm{d} t}=-\frac{\mathrm{d}\left[\mathrm{H}^{+}\right]}{\mathrm{d} t}=-\frac{\mathrm{d}[\mathrm{DMFc}]}{\mathrm{d} t} \approx 2 k_{1}[\mathrm{DMFc}]\left[\mathrm{H}^{+}\right]$

where $k_{1}$ is the rate constant of $\mathrm{DMFcH}^{+}$formation (Eq. (2)).

To study the kinetics of this process, $\mathrm{DMFc}^{+}$was reduced to DMFc at the SECM tip, thus the electrogenerated DMFc can then react with oxygen and protons according to Eq. (1), regenerating the starting material, $\mathrm{DMFc}^{+}$(Scheme 1 ). The protons were introduced into the DCE phase either by positively polarizing the liquid/liquid interface to such an extent that protons can be transferred from the aqueous to the oil phase (Scheme 1A) or by direct addition of an organic acid into the DCE phase (in this case, the w/ DCE interface is replaced by a solid conductive substrate, see Scheme 1B). Under these conditions, regeneration of $\mathrm{DMFc}^{+}$takes place by the overall homogeneous reaction (Eq. (1)), with the interfacial reaction as a minor contributor; Scheme $1 \mathrm{~A}$ only shows the major contributor for clarity. Hence, the system can be studied either with the w/DCE interface as the proton source or in the homogeneous phase by adding an organic acid directly into the solution.

\subsection{Simulations}

The ORR kinetics can be studied more conveniently in a homogeneous phase by adding an organic acid directly into the solution. The experimental evidence will be addressed in Section 4.2; however, to extract the kinetic rate constants of the homogeneous ORR quantitatively, a simulation model, employing COMSOL Multiphysics software and incorporating a solid conductive substrate in place of the liquid/liquid interface, along with an organic acid as the proton source, was built (see Scheme 1B). The merit of this strategy is the number of independent variables in this model is less than that in a model built on liquid/liquid interfacial design, simplifying the simulation drastically. $\mathrm{DMFc}^{+}$is reduced at the microelectrode tip, producing DMFc (reaction 6). DMFc will react homogeneously with protons and oxygen, and is oxidized back to $\mathrm{DMFc}^{+}$by means of bulk (Eq. (1)) and heterogeneous (substrate, Eq. (7)) reactions. The rate of reaction 1 can be estimated as shown in Eq. (5), where $k=2 k_{1} \cdot \mathrm{O}_{2}$ is assumed to be in excess (solubility of $\mathrm{O}_{2}$ in DCE is $1.4 \mathrm{mM}$ [51]) during the homogeneous reaction; the system under consideration is deemed open, such that $\mathrm{O}_{2}$ is continually replenished. In this way, the current profile of the tip approaching the conductive substrate is different between the cases with and without the homogeneous ORR. In the absence of homogeneous reac- tions $(k=0)$, DMFc was oxidized back to DMFc ${ }^{+}$directly on the solid substrate (Eq. (7)) in a close tip/substrate separation. While, less DMFc will be oxidized directly on the solid substrate due to a compressed current (concentration) profile of DMFc close to the tip surface in the presence of the competitive homogeneous ORR $(k \neq 0)$ [52]. The approach curves recorded at the tip are highly sensitive to the rate constant of the homogeneous chemical reaction and comparison and fitting between theoretical and experimental approach curves form the basis of the methodology described here.

$\mathrm{DMFc}^{+}+\mathrm{e}^{-} \rightarrow$ DMFc (tip)

$\mathrm{DMFc} \rightarrow \mathrm{DMFc}^{+}+\mathrm{e}^{-} \quad$ (solid substrate)

The details on calculations of approach curves considering mass transport of reactant species and kinetics of the homogeneous reaction will be given in the Appendix A.

\section{Experimental section}

\subsection{Chemicals}

All chemicals were analytical grade and used as received without further purification. Decamethylferrocene (DMFc) was purchased from Alfa Aesar. Bis(triphenylphosphoranylidene) ammonium chloride (BACl) and 1,2-dichloroethane (DCE) were obtained from Fluka. Sulfuric acid $\left(\mathrm{H}_{2} \mathrm{SO}_{4}, 95-97 \%\right)$ was sourced from Sigma-Aldrich, while lithium tetrakis(pentafluorophenyl)borate diethyl etherate (LiTB) was bought from Boulder Scientific. Bis(triphenylphosphoranylidene) ammonium tetrakis (pentafluorophenyl)borate (BATB) was prepared by metathesis of $1: 1$ mixtures of BACl and LiTB, in a methanol/water $(v / v=2)$ mixture, followed by recrystallization in acetone [53]. The organic acid HTB was prepared by shaking $x \mathrm{mM} \mathrm{LiTB}$ and $y \mathrm{mM} \mathrm{H}_{2} \mathrm{SO}_{4}(x \ll y)$ in aqueous phase with pure DCE for $1 \mathrm{~h}$, followed by the isolation of the DCE phase [50]. The obtained DCE solution is assumed to contain only HTB in $x \mathrm{mM}$, considering the extreme lipophilicity of $\mathrm{TB}^{-}$as phase transfer catalyst for $\mathrm{H}^{+} .5 \mathrm{mM} \mathrm{DMFc}^{+} \mathrm{TB}^{-}$with $5 \mathrm{mM}$ BATB as supporting electrolyte in DCE was prepared by two-phase shake flask reactions between an aqueous phase containing $5 \mathrm{mM}$ LiTB along with $50 \mathrm{mM} \mathrm{H}_{2} \mathrm{SO}_{4}$ and a DCE phase containing $5 \mathrm{mM}$ BATB and 5 mM DMFc. The biphasic mixture was stirred for $1 \mathrm{~h}$, followed by isolation of the DCE phase [16]. The aqueous solutions were prepared from ultrapure water $(18.2 \mathrm{M} \Omega \mathrm{cm})$ obtained from a Millipore-Q system.
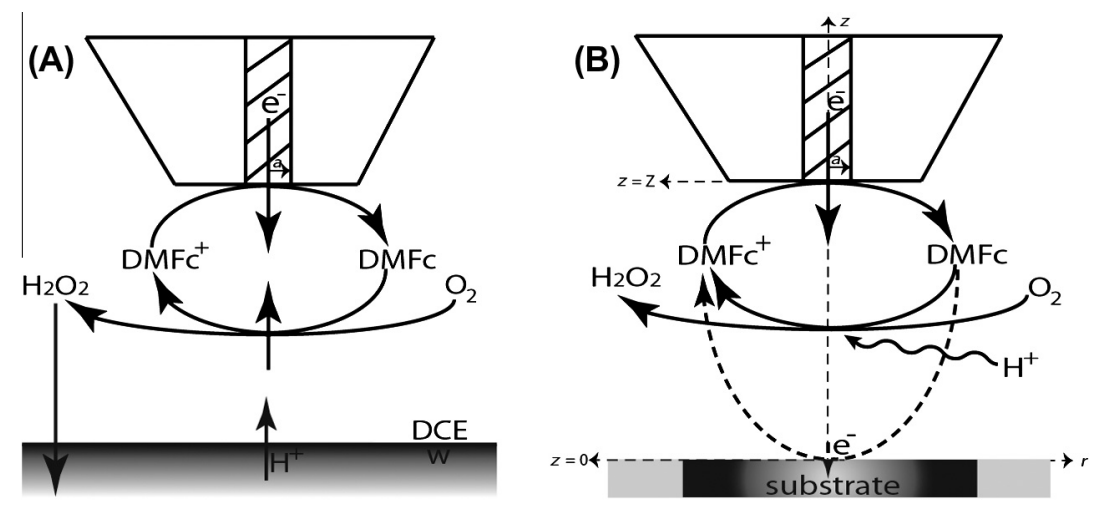

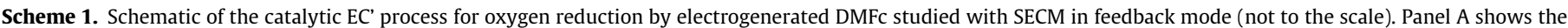

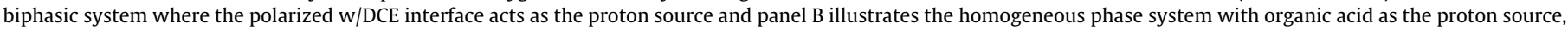
respectively. The thin dashed lines with arrows indicate the coordinate axes in panel B. The two experimental setups are detailed in Fig. $1 \mathrm{~A}$ and $\mathrm{B}$, respectively. 


\subsection{Electrochemical measurements}

All the electrochemical measurements were performed at ambient temperature $\left(20 \pm 2{ }^{\circ} \mathrm{C}\right)$ under aerobic conditions in a Faraday cage with a CHI900 electrochemical workstation (CH Instruments, Austin, USA) or an Autolab PGSTAT 30 potentiostat (Metrohm, Switzerland). The electrochemical cells are described in Fig. 1, including the setup for the liquid/liquid interface system as illustrated in Fig. 1A and that for homogeneous phase system drawn in Fig. 1B. For the liquid/liquid interface system, the reference electrode was a $\mathrm{Ag} / \mathrm{AgTB}$ wire (diameter $=0.5 \mathrm{~mm}$, made by electrolysis of a $\mathrm{Ag}$ wire in $10 \mathrm{mM}$ LiTB solution) inserted into a fine-tip glass capillary (outer/inner diameter $=591 / 130 \mu \mathrm{m}) \quad$ [54] immersed in the test solution. $\mathrm{A} \mathrm{Ag} / \mathrm{AgCl}$ electrode (diameter $=0.5 \mathrm{~mm}$ ) sealed in glass $(2 \mathrm{~mm}$ in overall diameter) was used as a substrate electrode for supporting the aqueous droplet $(5 \mu \mathrm{L}$, $1 \mathrm{M} \mathrm{HCl}$ ). A home-made glass-insulated carbon fiber microelectrode (diameter $=10 \mu \mathrm{m}, \mathrm{RG}=5.5$ ) or a commercial glassy carbon microelectrode (Princeton Applied, diameter $=10 \mu \mathrm{m}, \mathrm{RG}=5.5$ ) was used as the SECM probe in the DCE phase $\left(0.5 \mathrm{mM} \mathrm{DMFc}^{+} \mathrm{TB}^{-}\right.$ and 50 or $5 \mathrm{mM}$ BATB). Carbon electrodes were used since they have a sufficiently high overpotential for hydrogen evolution [18] to allow the selective separation of proton and $\mathrm{DMFc}^{+}$reduction current waves, simplifying the kinetic studies. A Pt wire was used as a counter electrode. The DCE phase and aqueous phase were saturated with each other before SECM studies. A set of approach curves were obtained by approaching the microelectrode (biased at a potential where a diffusion-limited steady-state current for the reduction of $\mathrm{DMFc}^{+}$is achieved) toward the DCE/w interface, while at the same time polarizing the interface at different Galvani potentials. All the approach curves started from a point far away from the interface and were stopped after the probe touched the aqueous phase. After each approach curve, the tip was cleaned to avoid any contamination that may have occurred through possible contact with the interface. The Galvani potential difference at the liquid/liquid interface was obtained by correcting the applied potential with respect to the standard ion transfer potential of tetraethylammonium $\left(\mathrm{TEA}^{+}\right), \Delta_{\mathrm{o}}^{\mathrm{w}} \phi_{\mathrm{TEA}^{+}}^{\mathrm{o}^{\prime}}=0.019 \mathrm{~V}$ or tetramethylammonium $\left(\mathrm{TMA}^{+}\right), \Delta_{\mathrm{o}}^{\mathrm{w}} \phi_{\mathrm{TMA}^{+}}^{\mathrm{o}^{\prime}}=0.160 \mathrm{~V}$ [55].

To clarify the reaction site for the ORR at the liquid/liquid interface, SECM studies on a soft interface were complemented with studies on a solid glassy carbon surface (diameter $=3 \mathrm{~mm}$ ), where another set of approach curves were conducted with a Pt microelectrode tip (diameter $=10 \mu \mathrm{m}, \mathrm{RG}=5.5$ ) over the glassy carbon surface (Fig. 1B). All other conditions were the same as those for the SECM experiments for the liquid/liquid interface. Fabrication of the Pt (diameter $=10$ or $25 \mu \mathrm{m}$ ) and carbon fiber (diameter $=10 \mu \mathrm{m}$ ) microelectrodes was performed as described elsewhere $[18,56]$.

For a quantitative determination of the kinetic constants in the homogeneous chemical reaction, a series of approach curves with the GC microelectrode (diameter $=10 \mu \mathrm{m}, \mathrm{RG}=8.6$ ) on a Pt substrate $(500 \mu \mathrm{m}$ diameter) were performed, employing the setup shown in Fig. 1B. The tip was first centered over the middle of the substrate by filling the cell with $2 \mathrm{mM} \mathrm{FcMeOH}$ solution in $100 \mathrm{mM} \mathrm{KNO}_{3}$ and measuring the $x$ and $y$ scans over the substrate in the feedback mode. The angle of the substrate was then adjusted with the tilt table so that both $x$ and $y$ scans were reasonably flat. Afterwards, the cell was emptied and washed with pure DCE solvent before introducing the test solution of $c a .0 .5 \mathrm{mM} \mathrm{DMFc}^{+} \mathrm{TB}^{-}$ with 2 equivalents of trifluoroacetic acid (TFA) as the organic acid into the cell. The tip was set to a potential for $\mathrm{DMFc}^{+}$reduction at a diffusion-limited rate, while the substrate was biased at a potential for diffusion-limited oxidation of DMFc to $\mathrm{DMFc}^{+}$. Then the approach curve was recorded at a speed of $0.5 \mu \mathrm{m} / \mathrm{s}$ and a step of $0.5 \mu \mathrm{m}$. The procedure was also repeated for 4 and 10 equivalents of TFA. For comparison of the experimental data with the simulated results, the tip current was normalized with the tip current in the bulk, and the distance at the end of the approach was adjusted to get the best possible correspondence with the experimental data. These experiments were conducted employing a custom-built SECM setup controlled by SECMx software [57] and with an IVIUM compactstat (IVIUM Technologies, The Netherlands).

\section{Results and discussion}

\subsection{Characterization by UV-Vis spectroscopy and voltammetry}

Careful examination of reaction kinetics requires that $\mathrm{H}^{+}$be inactive at the microelectrode tip over the same potential range for $\mathrm{DMFc}^{+}$reduction. The standard redox potentials for $\mathrm{DMFc}^{+} /$
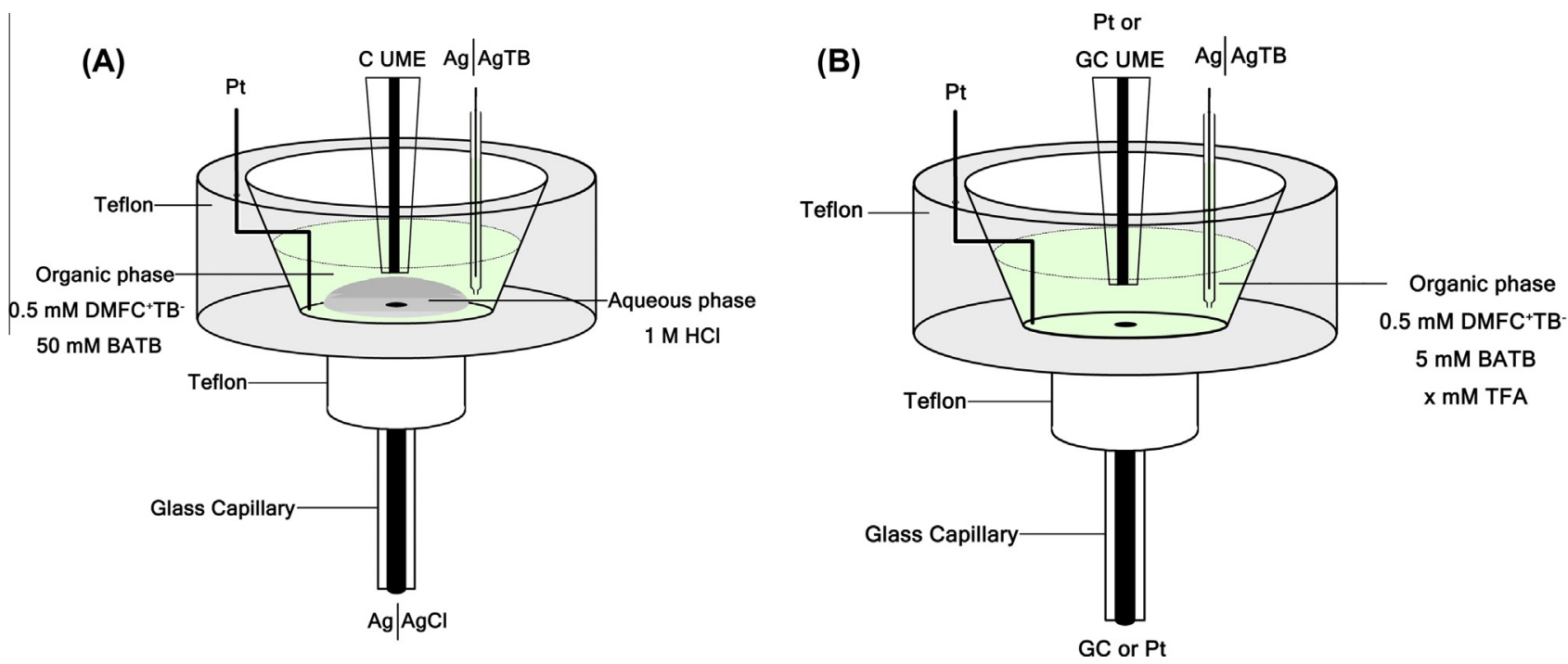

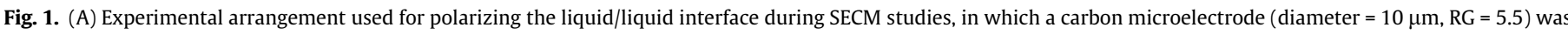

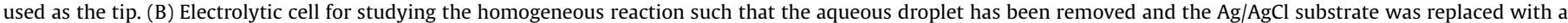

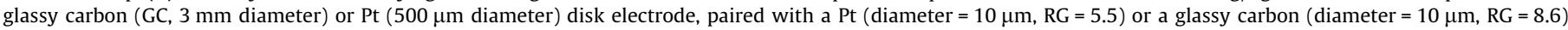
microelectrode, respectively. 
DMFC and $\mathrm{H}^{+} / \mathrm{H}_{2}$ in DCE phase are 0.07 and $0.55 \mathrm{~V}$, respectively [58]. To minimize the interference from the proton reduction at the tip electrode, electrode materials with high overpotentials for this reaction should be used. Earlier studies have demonstrated that carbon has a high overpotential for hydrogen evolution in DCE [18]; hence, the use of a carbon electrode allows the selective separation of proton and $\mathrm{DMFc}^{+}$reduction. Additionally, interference from $\mathrm{O}_{2}$ reduction was investigated under both aerobic and anaerobic conditions, such that the presence of $\mathrm{O}_{2}$ had no influence on the voltammetry at a carbon microelectrode for $\mathrm{DMFc}^{+} / \mathrm{DMFc}$ oxidation/reduction (data not shown). This was also the case for the study of ORR by 1,2-diferrocenylethane (DFCE) at a liquid/ liquid interface [18].

Fig. 2 compares the voltammetric profile obtained at a Pt and a carbon disk microelectrode in a DCE solution containing both HTB and $\mathrm{DMFc}^{+} \mathrm{TB}^{-}$. This illustrates that proton reduction occurs before $\mathrm{DMFc}^{+}$at a Pt surface, as the wave at ca. $0.32 \mathrm{~V} v s$. DMFc ${ }^{+} / \mathrm{DMFc}$, which has been assigned to hydrogen evolution, increases with increasing proton/acid concentration (solid line vs. dotted line). Linear sweep voltammetry (LSV) rather than CV was employed to avoid a severely distorted signal during the reverse potential scan due to the large amount of $\mathrm{H}_{2}$ evolved. As shown in Fig. 2, the high overpotential for $\mathrm{H}^{+}$reduction on carbon shifts its reduction to more negative potentials, allowing a clear separation of the DMFc ${ }^{+}$ and proton cathodic waves, with the difference in the half-wave potentials of more than $300 \mathrm{mV}$ (dashed line). This is in agreement with earlier results (see Fig. 3, in Ref. [18]); therefore, biasing the carbon microelectrode at $-0.15 \mathrm{~V}$ vs. $\mathrm{DMFc}^{+} / \mathrm{DMFc}$ allows the selective reduction of $\mathrm{DMFc}^{+}$at a diffusion-controlled steady state rate.

The produced $\mathrm{DMFc}^{+} \mathrm{TB}^{-}$in DCE solution was characterized by UV-Vis measurements and cyclic voltammetry with a carbon microelectrode, as illustrated in Fig. 3, to confirm that a $100 \%$ yield for $\mathrm{DMFC}^{+} \mathrm{TB}^{-}$was obtained. Normally, a fresh yellow solution of DMFc in DCE displays an absorption band in the UV-Vis spectrum at $\lambda_{\max }=425 \mathrm{~nm}$ (dashed line). However, after a two-phase shake flask experiment, using LiTB and $\mathrm{H}_{2} \mathrm{SO}_{4}$, the DCE phase turned green and displayed a new absorption band in the UV-Vis spectrum with a $\lambda_{\max }=779 \mathrm{~nm}$, indicating the presence of $\mathrm{DMFc}^{+}$(solid line in Fig. 3). Since the absorption band of DMFc at $\lambda_{\max }=425 \mathrm{~nm}$ disappeared completely, it can be assumed that the reaction was quantitative (i.e. 100\%). This assumption was confirmed by cyclic voltammetry in the DCE phase at a carbon microelectrode, where

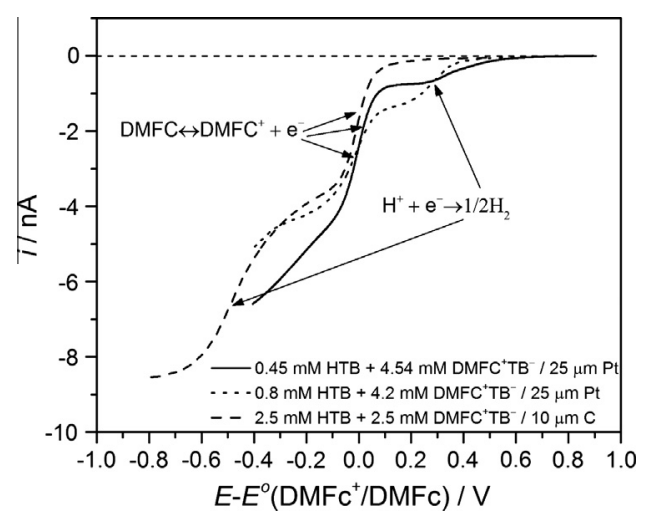

Fig. 2. Linear sweep voltammograms of $0.45 \mathrm{mM} \mathrm{HTB}+4.54 \mathrm{mM} \mathrm{DMFc}^{+} \mathrm{TB}^{-}$(solid line) and $0.8 \mathrm{mM} \mathrm{HTB}+4.2 \mathrm{mM} \mathrm{DMFc}^{+} \mathrm{TB}^{-}$(dotted line) in DCE on a Pt microelectrode (diameter $=25 \mu \mathrm{m}$ ) and of $2.5 \mathrm{mM} \mathrm{DMFc}^{+} \mathrm{TB}^{-}+2.5 \mathrm{mM}$ HTB (dashed line) in DCE on a carbon fiber microelectrode (diameter $=10 \mu \mathrm{m}$ ). For both conditions, $5 \mathrm{mM}$ BATB is added as the supporting electrolyte in the DCE phase. Scan rate was $20 \mathrm{mV} \mathrm{s}^{-1}$, with a $\mathrm{Ag} / \mathrm{AgTB}$ reference electrode and a Pt wire as the counter electrode.

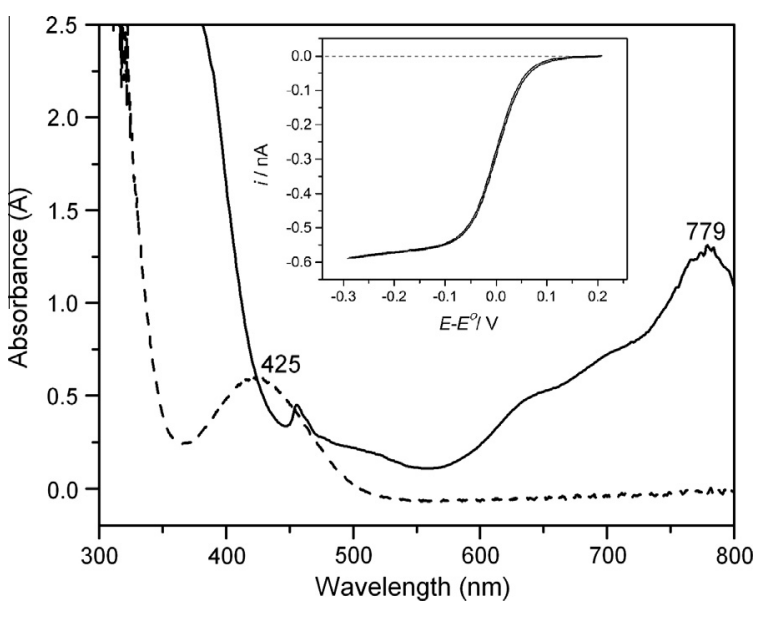

Fig. 3. UV-Vis spectrum of the prepared solution of $5 \mathrm{mM} \mathrm{DMFc}^{+} \mathrm{TB}^{-}$in $\mathrm{DCE}$ (solid line), supporting electrolyte is BATB. For the purpose of comparison, the spectrum of freshly prepared $5 \mathrm{mM}$ DMFc in DCE (dashed line) is also included. Inset: Cyclic voltammogram of $0.5 \mathrm{mM} \mathrm{DMFc} \mathrm{TB}^{-}$and $10 \mathrm{mM}$ BATB at a carbon microelectrode (diameter $=10 \mu \mathrm{m}$ ) in DCE, with a scan rate of $20 \mathrm{mV} \mathrm{s}^{-1}$.

only a pure steady-state cathodic current wave was observed during the forward scan (i.e. reduction of $\mathrm{DMFc}^{+}$), while the reverse scan superimposed exactly with the forward scan, showed a signal without any appreciable anodic component (see inset in Fig. 3). This voltammetric result also indicates that the formed $\mathrm{DMFc}^{+}$is very stable and no decomposition takes place in the time-scale of the experiment.

Fig. 4 shows the cyclic voltammograms obtained at the droplet $\mathrm{w} / \mathrm{DCE}$ interface in the three-electrode setup (see Fig. 1A) and at the conventional planar $w / D C E$ interface $\left(0.159 \mathrm{~cm}^{2}\right)$ in the fourelectrode setup [30]. The similarity inherent in these two voltammograms confirms the applicability of the three-electrode setup to polarize the liquid/liquid interface. The only difference is that the $\mathrm{CV}$ obtained in the four-electrode setup is sharper at the negative and positive potential limits, mostly due to $i R$ drop compensation. As discussed previously $[17,20,21,26]$, the potential window in the droplet case is limited by the transfer of $\mathrm{H}^{+}$and $\mathrm{Cl}^{-}$from water to DCE at positive and negative potentials, respectively. The voltammetric wave of $\mathrm{DMFc}^{+}$transfer cannot be observed under the present conditions as it is outside the negative limit of the potential

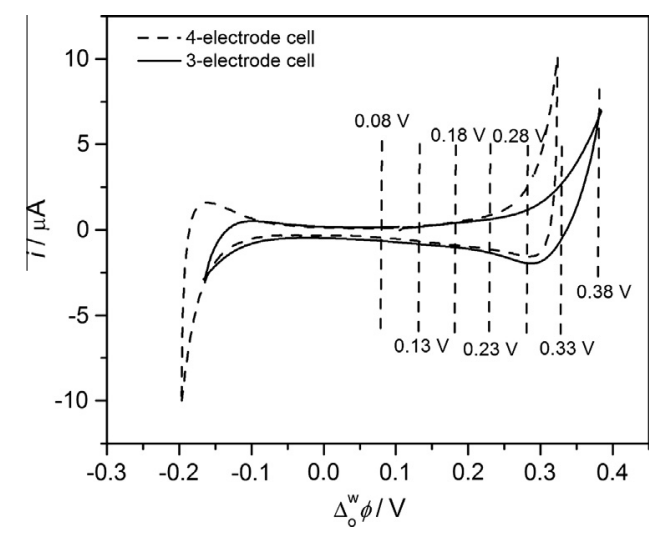

Fig. 4. Cyclic voltammograms of the w/DCE interface with a three-electrode (solid line, uncompensated) and four-electrode setup [30] (dashed line; the same cell composition as the three-electrode setup, but in addition a Ref. water solution of $1 \mathrm{mM} \mathrm{BACl}+10 \mathrm{mM} \mathrm{LiCl}$ was used for the DCE phase, and $i R$ drop was compensated). The vertical dashed lines represent the substrate Galvani potentials employed for the set of approach curves. The scan rate was $50 \mathrm{mV} \mathrm{s}^{-1}$, while other conditions were the same as those described for Fig. 1. 
window. By replacing $\mathrm{HCl}$ with $\mathrm{H}_{2} \mathrm{SO}_{4}$ as the aqueous electrolyte, the $\mathrm{DMFc}^{+}$signal can be observed owing to the more negative transfer potential of $\mathrm{HSO}_{4}^{-} / \mathrm{SO}_{4}^{2-}$ [17]. The vertical dashed lines on the 3-electrode cell CV (solid line) in Fig. 4 represent the different Galvani potential values employed for polarizing the interface during SECM feedback mode experiments (i.e. approach curves).

\subsection{SECM feedback mode in biphasic system}

Fig. 5A shows the experimental approach curves performed via approaching the microelectrode probe toward the DCE/w interface biased at the Galvani potentials highlighted in Fig. 4. A trend in the approach curves evolving from negative to positive feedback can be observed as the Galvani potential difference at the ITIES was gradually increased. The positive feedback can be explained as the regeneration of the initial species $-\mathrm{DMFc}^{+}$according to Eq. (1). The increase in the current starts from normalized distances higher than 50, when the interfacial potential difference was higher than $0.23 \mathrm{~V}$ in the Galvani potential scale. This is not in agreement with the typical approach curves obtained for interfacial processes studied by SECM (as seen from a series of approach curves obtained over the glassy-carbon substrate biased at different applied potentials, Fig. 5B). Typically, the normalized current is mainly perturbed at normalized distances smaller than 2 in the SECM approach curves obtained at the electrolyte/solid substrate interface. The fact that an increase in the recorded current is observed at much longer distances can be explained by the homogeneous reaction between the electrogenerated DMFc with protons diffusing into the bulk DCE phase from the liquid/liquid interface and dissolved oxygen in DCE. This is in agreement with the IT $-C_{1} C_{2}$ mechanism proposed by Stockmann et al. [35]. As it has been well recognized that the ion transfer across the ITIES is fast $\left(0.5-1 \mathrm{~cm} \mathrm{~s}^{-1}\right)$ [59], the polarization of the liquid/liquid interface fixes the interfacial proton concentration at the oil side to the value dictated by the Nernst equation (Eq. (8)), and then the protons start to diffuse into the bulk phase.

$\Delta_{\mathrm{o}}^{\mathrm{w}} \phi=\Delta_{\mathrm{o}}^{\mathrm{w}} \phi_{\mathrm{H}^{+}}^{\mathrm{o}^{\prime}}+\frac{R T}{F} \ln \left(\frac{C_{\mathrm{H}^{+}}^{\mathrm{o}}}{C_{\mathrm{H}^{+}}^{\mathrm{w}}}\right)$

where $\Delta_{0}^{\mathrm{w}} \phi_{\mathrm{H}^{+}}^{\mathrm{o}^{\prime}}$ is the formal transfer potential of $\mathrm{H}^{+}$and equals to $0.55 \mathrm{~V}[58], c_{\mathrm{H}^{+}}^{0}$ and $c_{\mathrm{H}^{+}}^{\mathrm{w}}$ are the proton concentrations in the organic and aqueous sides of the liquid/liquid interface, respectively. $c_{\mathrm{H}^{+}}^{\mathrm{w}}$ is assumed to be the same as the bulk value due to the high diffusion coefficient of $\mathrm{H}^{+}$in aqueous phase $\left(9.3 \times 10^{-5} \mathrm{~cm}^{2} \mathrm{~s}^{-1}\right)$ [60]. $R, T$, and $F$ have their usual meanings. Once the proton diffusion layer meets the tip, the tip current increases as described by the catalytic EC' process (Eqs. (2)-(4)).

The concentration profile of $\mathrm{H}^{+}$at the tip can be built based on the proton concentration at the oil side $\left(c_{\mathrm{H}^{+}}^{0}\right)$ from the Nernst equation (Eq. (8)) and the approach curves such as those drawn in Fig. 5A. The concentration profile equation derived from the Laplace transform is as follows:

$c_{\mathrm{H}^{+}}(x, t)=c_{\mathrm{H}^{+}}^{\mathrm{e}} \operatorname{erfc}\left[\frac{x}{2 \sqrt{D_{\mathrm{H}^{+}}^{\mathrm{o}} t}}\right]$

where $c_{\mathrm{H}^{+}}(x, t)$ is the $\mathrm{H}^{+}$concentration in DCE at the tip located at a distance $x$ from the interface and at time $t$, erfc is the complementary error function, $x=$ initial tip position $-v t$, in which $v$ is the approach rate $\left(1 \mu \mathrm{m} \mathrm{s}^{-1}\right)$ of the SECM tip, and $D_{\mathrm{H}^{+}}^{\circ}$ is the diffusion coefficient of $\mathrm{H}^{+}$in DCE, taken to be approximately $1 \times 10^{-5} \mathrm{~cm}^{2} \mathrm{~s}^{-1}$ [35].

Fig. $5 \mathrm{C}$ shows the normalized $\mathrm{H}^{+}$concentration profiles in the DCE phase at different times (dashed lines, left ordinate axis) and the $\mathrm{H}^{+}$concentration profile at the tip (solid line, left ordinate axis)
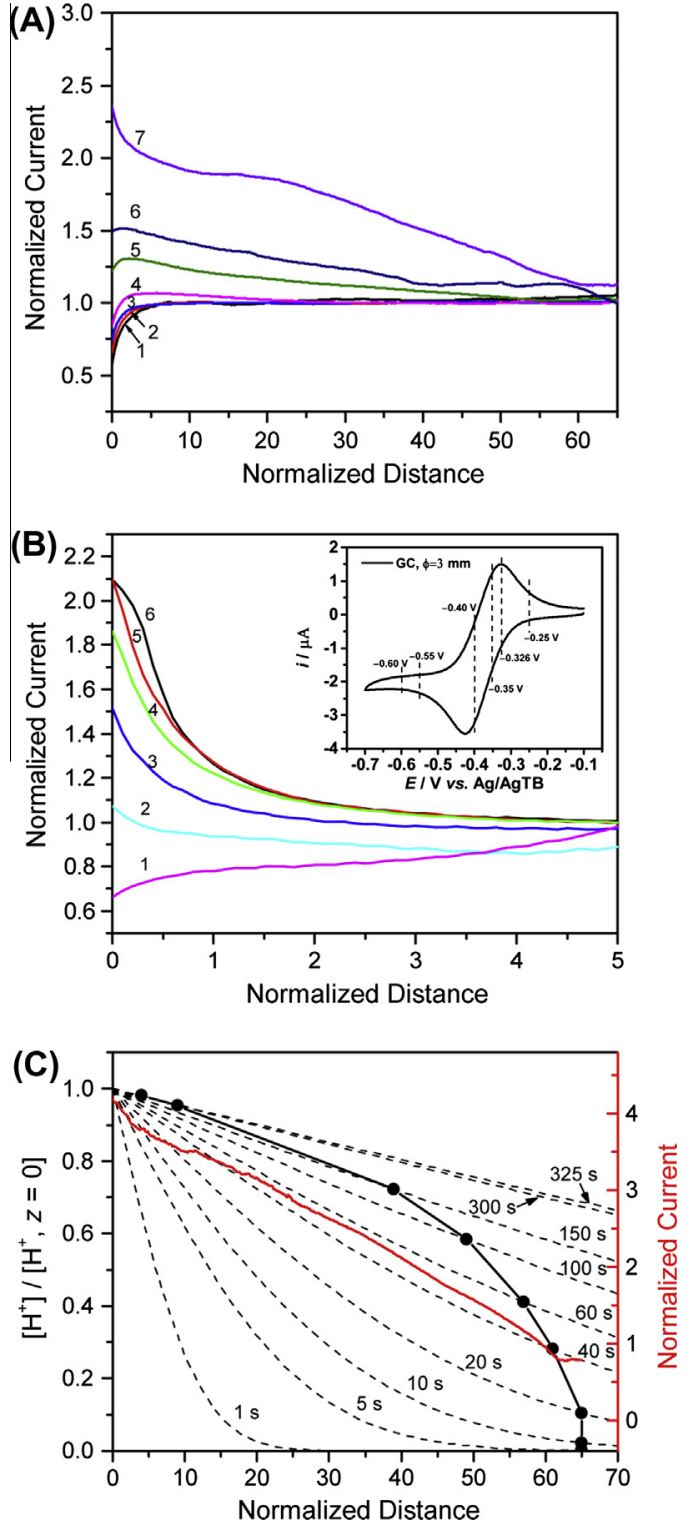

Fig. 5. (A) Experimental SECM approach curves obtained by biasing the w/DCE interface at different Galvani potentials, 0.08 (1), 0.13 (2), 0.18 (3), 0.23 (4), 0.28 (5), $0.33(6)$, and $0.38 \mathrm{~V}(7)$, respectively, while keeping the potential at $-0.15 \mathrm{~V}$ ( $v s$. $\mathrm{DMFc}^{+} / \mathrm{DMFc}$ ) for the mass transport controlled reduction of $\mathrm{DMFc}^{+}$at the carbon microelectrode tip (diameter $=10 \mu \mathrm{m}, \mathrm{RG}=5.5$ ). Approach rate was $1 \mu \mathrm{m} \mathrm{s}^{-1}$. (B) Experimental SECM approach curves obtained by approaching a Pt disk microelectrode (diameter $=10 \mu \mathrm{m}, \mathrm{RG}=5.5)$ biased at a potential $(-0.8 \mathrm{~V} v \mathrm{~s} . \mathrm{Ag} / \mathrm{AgTB})$ for diffusion-limited reduction of $\mathrm{DMFc}^{+}$toward the glassy carbon substrate biased at different potentials between -0.6 to $-0.25 \mathrm{~V}(v s$. Ag/AgTB) from down to top: -0.60 $(1),-0.55(2),-0.40(3),-0.35(4),-0.326(5)$, and $-0.25 \mathrm{~V}(6)$ with an approach rate of $1 \mu \mathrm{m} \mathrm{s}^{-1}$. Other conditions are the same as those in Fig. 1. Inset: Cyclic voltammogram at a glassy carbon electrode (diameter $=3 \mathrm{~mm}$, substrate) immersed into a solution of $0.5 \mathrm{mM} \mathrm{DMFc}^{+} \mathrm{TB}^{-}$and $50 \mathrm{mM}$ BATB in DCE, with a scan rate of $50 \mathrm{mV} \mathrm{s}^{-1}$. (C) The normalized $\mathrm{H}^{+}$concentration profiles for different times (dashed lines, left ordinate axis) and the $\mathrm{H}^{+}$concentration profile at the tip moving toward the DCE/w interface at specific times shown on the dashed lines (solid line, left ordinate axis), built based on the Eq. (9) and the approach curve (red line, right ordinate axis) obtained at a Galvani potential difference of $0.38 \mathrm{~V}$ in Fig. 4. Instrumental parameters: The quiet time was $20 \mathrm{~s}$ before the approach curve experiment and the initial tip position was at $325 \mu \mathrm{m}$ from the DCE/w interface. (For interpretation of the references to colour in this figure legend, the reader is referred to the web version of this article.)

at an applied Galvani potential difference of $0.38 \mathrm{~V}$ in Fig. 4, built based on Eq. (9) and the approach curve in Fig. 5C (red line, right ordinate axis). It can be seen from Fig. $5 \mathrm{C}$ that the $\mathrm{H}^{+}$concentration is noticeable even at a normalized distance of more than 50 , in 
agreement with the observations from Fig. 5A. Additionally, the shapes of the $\mathrm{H}^{+}$concentration profile at the tip and the approach curve are in a fair agreement. This provides evidence that the ORR mainly occurs in the bulk DCE phase, corroborating earlier findings [35]. Nevertheless, it should be stressed that the reproducibility between approach curves was poor as can be seen from comparison between the approach curve obtained at a Galvani potential difference of $0.38 \mathrm{~V}$ in Figs. $5 \mathrm{~A}$ and $\mathrm{C}$. The current signal obtained at the tip was not always stable; this likely due to some surface contamination. This was confirmed by slow addition of HTB into the DMFc solution and consecutive measurements of microelectrode voltammograms after each addition. The steady-state current decreased upon addition of HTB, but could be recovered by polishing the tip surface. So, another strategy, illustrated in Scheme 1B and Fig. 1B, was employed to extract the kinetic rate constant of the ORR, which will be discussed in Section 4.3.

Fig. 5A also shows a slight increase in the tip current close to the interface, when the Galvani potential difference was less than $0.23 \mathrm{~V}$. This can be explained by interfacial oxygen reduction when the electrogenerated DMFc reaches the DCE/w interface. Recently, SECM measurements using perchlorate as the common ion to polarize the liquid/liquid interface have shown that the driving force for oxygen reduction is high enough so that protons are not needed to transfer into the oil phase to trigger the reaction [31]. However, the heterogeneous reaction is much slower than the homogeneous reaction. Very recently, four-electrode cell measurements under anaerobic conditions in combination with finite element method simulations [35] have shown that DMFc can only slightly facilitate proton transfer $\left(\mathrm{DMFcH}^{+}\right.$formation constant of ca. $0.5 \mathrm{~m}^{3} \mathrm{~mol}^{-1} \mathrm{~s}^{-1}$ in DCE) across the polarized liquid/liquid interface. Hence, an additional reason for the slight increase in the tip current close to the interface, while keeping interfacial Galvani potential difference at values that cannot transfer protons into the DCE phase, can be explained by a homogeneous reaction mechanism [61]. In that case, the electrogenerated DMFc diffuses into the water droplet and reacts with $\mathrm{O}_{2}$ and $\mathrm{H}^{+}$at the aqueous side of the interface, forming $\mathrm{DMFc}^{+}$that is transferred back to the organic phase at potentials higher than the observed half-wave potential for $\mathrm{DMFc}^{+}$transfer (ca. $-0.3 \mathrm{~V}$ in Galvani scale). Subsequently, $\mathrm{DMFc}^{+}$is available for reduction at the SECM tip, forming a feedback loop. The superiority of homogeneous over heterogeneous regeneration of $\mathrm{DMFc}^{+}$can be ascribed to the drastic difference in the reaction field thickness between these two conditions [61]. The fact that a third order reaction is kinetically unfavorable also accounts for the small possibility of a heterogeneous reaction. This phenomenon has been observed previously for studies of ORR at the liquid/liquid interface by DMFc [28] and DFcE [18].

The same methodology developed here was also used to try to determine the kinetics of oxygen reduction by tetrathiafulvalene at the ITIES, but the results showed that the reaction between oxygen and TTF was too slow to show any significant changes in the current. This was not unexpected, as the completion of the reaction between $1 \mathrm{mM}$ TTF, $10 \mathrm{mM} \mathrm{HCl}$, and $10 \mathrm{mM}$ LiTB was reported to take more than $80 \mathrm{~h}$ [19].

\subsection{SECM feedback mode in the homogeneous phase}

As shown in the previous section, oxygen reduction by DMFc occurs mostly homogeneously in the DCE phase. Simulations of the system described in the previous section are difficult to compare with the experimental results due to the complexity of the system that involves both the moving tip and macro-scale diffusion of transferred protons into the bulk DCE toward the approaching tip. For the sake of simplicity, the reaction was studied in the homogeneous phase. A $500 \mu \mathrm{m}$ diameter Pt electrode was used as the substrate and a GC microelectrode of $10 \mu \mathrm{m}$ diameter used as the tip. This procedure was also repeated with addition of 4 and 10 equivalents of TFA. TFA was used since a more stable current was obtained in comparison with $\mathrm{HTB}$, that lead to considerable fouling of the tip and thus fluctuations of the signal.

The recorded curves were compared to the simulated ones to estimate the kinetic rate constant for the homogeneous reaction as shown in Fig. 6.

Fig. 6 shows that the apparent rate constant for all the TFA concentrations seems to be quite similar, such that the apparent reaction rate constant $-k$ can be estimated as $c a .0 .2-0.5 \mathrm{~m}^{3} \mathrm{~mol}^{-1} \mathrm{~s}^{-1}$. More accurate determination of the rate is not possible with this method, as the differences between simulated curves are quite small in this kinetics range. The simulations in Fig. 6 were done for the simple second-order reaction mechanism where DMFc and protons (and $\mathrm{O}_{2}$ ) react in the bulk phase generating $\mathrm{DMFc}^{+}$and other products. For ORR, the rate determining step has been identified as protonation of DMFc to form DMFc- $\mathrm{H}^{+}$[35]. The rate constant $k_{1}$ for the DMFc- $\mathrm{H}^{+}$formation can be related to $k$ simply by dividing it by a factor of two. This gives an estimate for $k_{1}$ as $c a$. $0.1-0.25 \mathrm{~m}^{3} \mathrm{~mol}^{-1} \mathrm{~s}^{-1}$, which further corroborates the value of
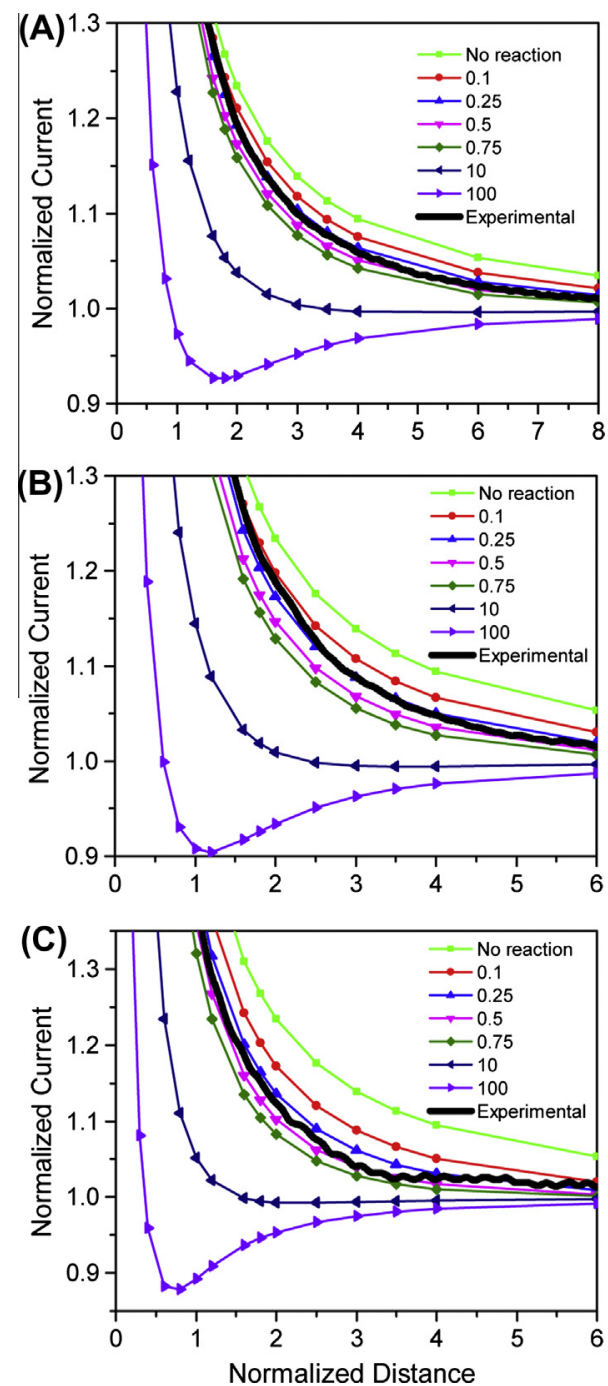

Fig. 6. Comparison of the measured approach curves (thick black lines) to the simulated ones for the EC' mechanism $\left(k=0,0.1,0.25,0.5,0.75,10,100 \mathrm{~m}^{3} \mathrm{~mol}^{-1}\right.$ $\mathrm{s}^{-1}, \mathrm{RG}=8.6$ ), in positive feedback mode. Experimental conditions: $10 \mu \mathrm{m}$ diameter GC microelectrode with a RG of 8.6 as the SECM tip and $500 \mu \mathrm{m}$ diameter Pt disk as the substrate. $0.5 \mathrm{mM} \mathrm{DMFc}^{+} \mathrm{TB}^{-}$and TFA acid with the concentration from top to bottom: $1 \mathrm{mM}$ (panel A), $2 \mathrm{mM}$ (panel B) and $5 \mathrm{mM}$ (panel C) in DCE, was used as the test solution, plus $5 \mathrm{mM}$ BATB added as the supporting electrolyte. 
$0.5 \mathrm{~m}^{3} \mathrm{~mol}^{-1} \mathrm{~s}^{-1}$ estimated from finite element simulations of the cyclic voltammetry at ITIES [35]. This shows that COMSOL simulations can be very good tools for analyzing reaction rates for complicated chemical reactions. The slightly smaller value obtained by the present experiments could be explained by the lower acidity of TFA compared to HTB present in the previous cyclic voltammetry experiments [35]. However, simulations show that this method would be more sensitive for even faster reactions and that the sensitivity can be increased by increasing concentration of protons.

\section{Conclusions}

We demonstrated that the combination of conventional electrochemistry at a liquid/liquid interface (enabled by the three-electrode strategy) with SECM in a feedback mode can be used to study the complicated kinetics of the oxygen reduction reaction at a biphasic system (i.e. catalytic EC' process). The present results confirmed that the liquid/liquid interface works as a proton pump controlled by the interfacial potential difference. The protons in the organic phase then participate in the reduction of dissolved oxygen by DMFc in DCE. Moreover, it was shown experimentally that the ORR mainly takes place in the bulk DCE phase when sufficient Galvani potential at the interface is applied. The kinetic rate constant for the chemical reaction between DMFc and $\mathrm{H}^{+}$was estimated as ca. $0.1-0.25 \mathrm{~m}^{3} \mathrm{~mol}^{-1} \mathrm{~s}^{-1}$, further confirming the voltammetric data analyzed by FEM through COMSOL [35]. The developed methodology can be used as a screening tool to characterize other electron donors or catalysts used for the oxygen reduction reaction or other energy-related reactions at the liquid/liquid interface.

\section{Conflict of interest}

The authors declare no conflict of interest.

\section{Acknowledgments}

The authors thank the Polish-Swiss Research Program, Project PSPB-035/2010: "Electrocatalysis at droplets", the China Scholarship Council (CSC), the Academy of Finland (Grant No. 133261) and EPFL for the financial support. H.D. also acknowledges the kind help from Dr./Prof. Fei Li (Xi'an Jiaotong University, China) and Dr. Manuel A. Méndez (LEPA, EPFL) for this work.

\section{Appendix A}

Migration effects are assumed to be negligible in the presence of a large excess of a supporting electrolyte, so that mass transport mainly occurs by diffusion and can be described using Fick's laws with the corresponding equations in axial-symmetric, cylindrical coordinates ( $r$, radial, and $z$, normal, coordinates with the origin at the center of the substrate disk). These can be written as the following Eqs. (A1)-(A3) in a steady-state mode.

$\frac{\partial c_{\mathrm{DMFc}^{+}}}{\partial t}=D_{\mathrm{DMFc}^{+}}\left(\frac{\partial^{2} c_{\mathrm{DMFc}^{+}}}{\partial z^{2}}+\frac{\partial^{2} c_{\mathrm{DMFc}^{+}}}{\partial r^{2}}+\frac{1}{r} \frac{\partial c_{\mathrm{DMFc}^{+}}}{\partial r}\right)+k c_{\mathrm{DMFC}} c_{\mathrm{H}^{+}}=0$

$\frac{\partial c_{\mathrm{DMFc}}}{\partial t}=D_{\mathrm{DMFc}}\left(\frac{\partial^{2} c_{\mathrm{DMFc}}}{\partial z^{2}}+\frac{\partial^{2} c_{\mathrm{DMFc}}}{\partial r^{2}}+\frac{1}{r} \frac{\partial c_{\mathrm{DMFc}}}{\partial r}\right)-k c_{\mathrm{DMFc}} c_{\mathrm{H}^{+}}=0$

$\frac{\partial c_{\mathrm{H}^{+}}}{\partial t}=D_{\mathrm{H}^{+}}\left(\frac{\partial^{2} c_{\mathrm{H}^{+}}}{\partial z^{2}}+\frac{\partial^{2} c_{\mathrm{H}^{+}}}{\partial r^{2}}+\frac{1}{r} \frac{\partial c_{\mathrm{H}^{+}}}{\partial r}\right)-k c_{\mathrm{DMFc}} c_{\mathrm{H}^{+}}=0$ where $c_{\mathrm{i}}$ and $D_{\mathrm{i}}$ are the concentration and diffusion coefficient of species $i$ and $k$ is the rate constant of the homogeneous chemical reaction in the organic solution (Eq. (1)).

The boundary conditions are:

$$
\begin{aligned}
D_{\mathrm{DMFc}^{+}} \frac{\partial c_{\mathrm{DMFc}^{+}}}{\partial z} & =k_{f, T} c_{\mathrm{DMFc}^{+}}-k_{b, T} c_{\mathrm{DMFc}} \\
& =-D_{\mathrm{DMFc}} \frac{\partial c_{\mathrm{DMFc}}}{\partial z}, D_{\mathrm{H}^{+}} \frac{\partial c_{\mathrm{H}^{+}}}{\partial z} \\
& =0 \quad(\text { tip electrode surface, } z=Z)
\end{aligned}
$$

$$
\begin{aligned}
D_{\mathrm{DMFc}^{+}} \frac{\partial c_{\mathrm{DMFc}^{+}}}{\partial z} & =D_{\mathrm{DMFc}} \frac{\partial c_{\mathrm{DMFc}}}{\partial z}=D_{\mathrm{H}^{+}} \frac{\partial c_{\mathrm{H}^{+}}}{\partial z} \\
& =0 \quad \text { (glass insulating sheath) }
\end{aligned}
$$

$D_{\mathrm{DMFc}} \frac{\partial c_{\mathrm{DMFc}}}{\partial z}=k_{f, S} c_{\mathrm{DMFc}}-k_{b, S} c_{\mathrm{DMFc}^{+}}=-D_{\mathrm{DMFc}^{+}} \frac{\partial c_{\mathrm{DMFc}^{+}}}{\partial z}$,

$D_{\mathrm{H}^{+}} \frac{\partial c_{\mathrm{H}^{+}}}{\partial z}=0 \quad($ solid substrate, $z=0)$

$c_{\mathrm{DMFc}^{+}}=c_{\mathrm{DMFc}^{+}}^{*}$,

$c_{\mathrm{DMFC}}=0$,

$c_{\mathrm{H}^{+}}=c_{\mathrm{H}^{+}}^{*} \quad$ (open boundaries far from the tip)

Eqs. (A4) and (A6) indicate that protons are inert at the microelectrode tip and at the substrate. $k_{f, T}$ and $k_{b, T}$ are the rate constants of the forward and backward reactions at the tip (reaction 6), and $k_{f, S}$ and $k_{b, S}$ are the rate constants of the forward and backward reactions at the substrate (Eq. (7)). The reaction kinetics at the electrodes are set so that $c_{\mathrm{DMFc}^{+}}(z=\mathrm{Z}, r, t \neq 0)=0$ at the surface of the tip, and $c_{\mathrm{DMFc}}(z=0, r, t \neq 0)=0$ at the surface of the substrate. Here $k_{b, T}$ is set to zero, $k_{f, T}=1 \times 10^{6}, k_{b, S}$ is set to zero, and $k_{f, S}=1 \times 10^{6}$. Far from the electrode the concentrations reach the bulk values. The initial conditions over all space (all $r$, all $z$ ) are

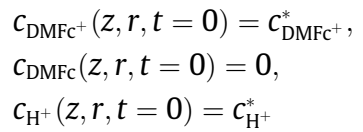

Eq. (A8) describes that initially there is only $\mathrm{DMFc}^{+}$and protons present in the system. Computational approach curves were obtained by varying the position of the tip in the simulations, while a series of working curves were obtained for different values of $k$. To compare the computational and experimental results, experimentally obtained normalized currents were calculated as follows.

$I=\frac{i_{\mathrm{UME}}}{i_{\mathrm{UME}, \infty}}$

$i_{\mathrm{UME}}=\frac{\pi}{2} \int_{0}^{a} \frac{\partial c}{\partial z} r d r, \quad$ at $z=Z$

$i_{\mathrm{UME}, \infty}=\frac{\pi}{2} \int_{0}^{a} \frac{\partial c}{\partial z} r d r, \quad$ at $z=Z, Z \rightarrow \infty$

where $i_{\mathrm{UME}, \infty}$ is the steady-state diffusion-limited tip current for reduction of $\mathrm{DMFc}^{+}$when the tip is far from the substrate. This approach allows for better comparison of simulated and experimental data, as $i_{\mathrm{UME}, \infty}$ can always be measured and used for current normalization. In the absence of protons or without a homogenous reaction $(k=0)$

$i_{\mathrm{UME}, \infty}=4 \mathrm{FaD}_{\mathrm{DMFc}^{+}} c_{\mathrm{DMFc}^{+}}^{*}$

where $a$ is the radius of the carbon or glassy-carbon microelectrode.

The model was validated by simulating approach curves without any homogeneous reactions $(k=0)$ and comparing the results with the analytical expressions for positive feedback [62]. The 
obtained approach curve differs from the analytical solution by less than $2.5 \%$.

\section{References}

[1] P. Mitchell, Nature 191 (1961) 144-148.

[2] D.A. Proshlyakov, M.A. Pressler, C. DeMaso, J.F. Leykam, D.L. DeWitt, G.T. Babcock, Science 290 (2000) 1588-1591.

[3] M. Blank, S. Feig, Science 141 (1963) 1173-1174.

[4] Z. Samec, Pure Appl. Chem. 76 (2004) 2147-2180.

[5] H.H. Girault, Electrochemistry at liquid-liquid interfaces, in: A.J. Bard, C.G. Zoski (Eds.), Electroanalytical Chemistry, vol. 23, CRC Press, Boca Raton, FL, 2010, pp. 1-104.

[6] Z. Samec, V. Mareček, J. Koryta, M.W. Khalil, J. Electroanal. Chem. Interfacial Electrochem. 83 (1977) 393-397.

[7] C. Shi, F.C. Anson, Anal. Chem. 70 (1998) 3114-3118.

[8] S. Ulmeanu, H.J. Lee, D.J. Fermin, H.H. Girault, Y. Shao, Electrochem. Commun. 3 (2001) 219-223.

[9] G. Taylor, H.H. Girault, J. Electroanal. Chem. 208 (1986) 179-183.

[10] V.J. Cunnane, G. Geblewicz, D.J. Schiffrin, Electrochim. Acta 40 (1995) 3005 3014.

[11] H. Ohde, K. Maeda, Y. Yoshida, S. Kihara, J. Electroanal. Chem. 483 (2000) 108116.

[12] B. Steiger, F.C. Anson, Inorg. Chem. 39 (2000) 4579-4585.

[13] T.D. Chung, F.C. Anson, J. Electroanal. Chem. 508 (2001) 115-122.

[14] P. Liljeroth, B.M. Quinn, K. Kontturi, Langmuir 19 (2003) 5121-5127.

[15] A. Trojánek, J. Langmaier, Z. Samec, Electrochem. Commun. 8 (2006) 475-481.

[16] B. Su, R.P. Nia, F. Li, M. Hojeij, M. Prudent, C. Corminboeuf, Z. Samec, H.H Girault, Angew. Chem. Int. Ed. 47 (2008) 4675-4678.

[17] F. Li, B. Su, F.C. Salazar, R.P. Nia, H.H. Girault, Electrochem. Commun. 11 (2009) $473-476$.

[18] H. Deng, P. Peljo, F. Cortés-Salazar, P. Ge, K. Kontturi, H.H. Girault, J. Electroanal. Chem. 681 (2012) 16-23.

[19] A.J. Olaya, P. Ge, J.F. Gonthier, P. Pechy, C. Corminboeuf, H.H. Girault, J. Am. Chem. Soc. 133 (2011) 12115-12123.

[20] I. Hatay, B. Su, F. Li, M.A. Méndez, T. Khoury, C.P. Gros, J.M. Barbe, M. Ersoz, Z. Samec, H.H. Girault, J. Am. Chem. Soc. 131 (2009) 13453-13459.

[21] I. Hatay, B. Su, M.A. Méndez, C. Corminboeuf, T. Khoury, C.P. Gros, M. Bourdillon, M. Meyer, J.M. Barbe, M. Ersoz, S. Záliŝ, Z. Samec, H.H. Girault, J. Am. Chem. Soc. 132 (2010) 13733-13741.

[22] A.J. Olaya, D. Schaming, P.F. Brevet, H. Nagatani, H.J. Xu, M. Meyer, H.H. Girault, Angew. Chem. Int. Ed. 51 (2012) 6447-6451.

[23] A.J. Olaya, D. Schaming, P.F. Brevet, H. Nagatani, T. Zimmermann, J. Vanicek, H.J. Xu, C.P. Gros, J.M. Barbe, H.H. Girault, J. Am. Chem. Soc. 134 (2012) 498506.

[24] R. Partovi-Nia, B. Su, F. Li, C.P. Gros, J.M. Barbe, Z. Samec, H.H. Girault, Chem. Eur. J. 15 (2009) 2335-2340.

[25] R. Partovi-Nia, B. Su, M.A. Méndez, B. Habermeyer, C.P. Gros, J.M. Barbe, Z Samec, H.H. Girault, ChemPhysChem 11 (2010) 2979-2984.

[26] B. Su, I. Hatay, A. Trojánek, Z. Samec, T. Khoury, C.P. Gros, J.M. Barbe, A. Daina, P.A. Carrupt, H.H. Girault, J. Am. Chem. Soc. 132 (2010) 2655-2662.

[27] A. Trojánek, J. Langmaier, B. Su, H.H. Girault, Z. Samec, Electrochem. Commun. 11 (2009) 1940-1943.

[28] B. Su, I. Hatay, F. Li, R. Partovi-Nia, M.A. Méndez, Z. Samec, M. Ersoz, H.H. Girault, J. Electroanal. Chem. 639 (2010) 102-108.
[29] P. Peljo, T. Rauhala, L. Murtomäki, T. Kallio, K. Kontturi, Int. J. Hydrogen Energy 36 (2011) 10033-10043.

[30] P. Peljo, L. Murtomäki, T. Kallio, H.J. Xu, M. Meyer, C.P. Gros, J.M. Barbe, H.H. Girault, K. Laasonen, K. Kontturi, J. Am. Chem. Soc. 134 (2012) 5974-5984.

[31] J. Jedraszko, W. Nogala, W. Adamiak, E. Rozniecka, I. Lubarska-Radziejewska, H.H. Girault, M. Opallo, J. Phys. Chem. C 117 (2013) 20681-20688.

[32] J. Jedraszko, W. Nogala, W. Adamiak, H.H. Girault, M. Opallo, Electrochem. Commun. 43 (2014) 22-24

[33] A. Trojánek, J. Langmaier, Z. Samec, Electrochim. Acta 82 (2012) 457-462.

[34] A. Trojánek, J. Langmaier, S. Záliš, Z. Samec, Chem. Commun. 48 (2012) 40944096.

[35] T. Jane Stockmann, H. Deng, P. Peljo, K. Kontturi, M. Opallo, H.H. Girault, J. Electroanal. Chem. 729 (2014) 43-52.

[36] A.J. Bard, F.R.F. Fan, J. Kwak, O. Lev, Anal. Chem. 61 (1989) 132-138.

[37] A.J. Bard, F.R.F. Fan, D.T. Pierce, P.R. Unwin, D.O. Wipf, F. Zhou, Science 254 (1991) 68-74.

[38] C. Wei, A.J. Bard, M.V. Mirkin, J. Phys. Chem. 99 (1995) 16033-16042.

[39] M.V. Mirkin, M. Tsionsky, Charge-transfer at the liquid/liquid interface, in: A.J. Bard, M.V. Mirkin (Eds.), Scanning Electrochemical Microscopy, second ed., Marcel Dekker, New York, 2001, pp. 299-342.

[40] P.R. Unwin, A.J. Bard, J. Phys. Chem. 95 (1991) 7814-7824.

[41] F. Zhou, P.R. Unwin, A.J. Bard, J. Phys. Chem. 96 (1992) 4917-4924.

[42] R.D. Martin, P.R. Unwin, J. Chem. Soc., Faraday Trans. 94 (1998) 753-759.

[43] P.R. Unwin, Kinetics of homogeneous reactions coupled to heterogeneous electron transfer, in: A.J. Bard, M.V. Mirkin (Eds.), Scanning Electrochemical Microscopy, second ed., Marcel Dekker, New York, 2001, pp. 241-298.

[44] G. Wittstock, M. Burchardt, S.E. Pust, Y. Shen, C. Zhao, Angew. Chem. Int. Ed. 46 (2007) 1584-1617.

[45] J.L. Fernández, A.J. Bard, Anal. Chem. 75 (2003) 2967-2974.

[46] J.L. Fernández, D.A. Walsh, A.J. Bard, J. Am. Chem. Soc. 127 (2005) 357-365.

[47] A.J. Bard, L.R. Faulkner, Electrochemical Methods, second ed., John Wiley \& Sons, New York, 2001.

[48] M. Fleischmann, F. Lasserre, J. Robinson, D. Swan, J. Electroanal. Chem. Interfacial Electrochem. 177 (1984) 97-114.

[49] S. Cannan, J. Cervera, R.J. Steliaros, E. Bitziou, A.L. Whitworth, P.R. Unwin, Phys. Chem. Chem. Phys. 13 (2011) 5403-5412.

[50] B. Su, I. Hatay, P.Y. Ge, M. Mendez, C. Corminboeuf, Z. Samec, M. Ersoz, H.H. Girault, Chem. Commun. 46 (2010) 2918-2919.

[51] P. Luehring, A. Schumpe, J. Chem. Eng. Data 34 (1989) 250-252.

[52] J. Galceran, S.L. Taylor, P.N. Bartlett, J. Electroanal. Chem. 506 (2001) 65-81.

[53] D.J. Fermín, H.D. Duong, Z. Ding, P.F. Brevet, H.H. Girault, Phys. Chem. Chem. Phys. 1 (1999) 1461-1467.

[54] T.J. Smith, K.J. Stevenson, Reference electrodes, in: C.G. Zoski (Ed.), Handbook of Electrochemistry, Elsevier, Amsterdam, 2007, pp. 73-110.

[55] T. Wandlowski, V. Mareček, Z. Samec, Electrochim. Acta 35 (1990) 1173-1175.

[56] F. Gao, Y. Yang, J. Liu, H. Shao, Ionics 16 (2010) 45-50.

[57] C.N. Kirchner, K.H. Hallmeier, R. Szargan, T. Raschke, C. Radehaus, G. Wittstock, Electroanalysis 19 (2007) 1023-1031.

[58] I. Hatay, B. Su, F. Li, R. Partovi-Nia, H. Vrubel, X. Hu, M. Ersoz, H.H. Girault, Angew. Chem. Int. Ed. 48 (2009) 5139-5142.

[59] Z. Samec, Electrochim. Acta 84 (2012) 21-28.

[60] S.H. Lee, J.C. Rasaiah, J. Chem. Phys. 135 (2011) 124505-1-124505-10.

[61] H. Hotta, S. Ichikawa, T. Sugihara, T. Osakai, J. Phys. Chem. B 107 (2003) $9717-$ 9725.

[62] R. Cornut, C. Lefrou, J. Electroanal. Chem. 621 (2008) 178-184. 